\section{Finger necrosis with eosinophilia and symmetrical occlusion of the peripheral artery}

\section{CASE PRESENTATION}

A 59-year-old man with hypertension, dyslipidemia and a current smoking history had presented with bilateral painful finger ulcers (figure 1A). The patient was referred to our hospital for the diagnosis and treatment. On his arrival, his fingers showed the development from ulcer to necrosis during the 3 weeks (figure 1B). Diagnostic angiography at the previous hospital had revealed symmetrical occlusions of the forearm and crural arteries (figure 2). Laboratory blood tests demonstrated an eosinophilia $(21 \%, 1743$ cells $/ \mu \mathrm{L})$ with marked elevation of $\mathrm{IgE}(4200 \mathrm{mg} / \mathrm{dL})$ as well as inflammatory reaction such as erythrocyte sedimentation rate $84 \mathrm{~mm} / \mathrm{h}$ and C-reactive protein $0.85 \mathrm{mg} / \mathrm{dL}$. There was no evidence of thrombophilia, and autoantibodies were negative. A skin biopsy from the border of the necrosis demonstrated perivascular considerable infiltration of inflammatory cells including eosinophils (figure 3).

\section{QUESTION}

What is the most likely diagnosis?
A. Buerger's disease
B. Eosinophilic vasculitis
C. Drug abuse
D. Cholesterol embolisation syndrome
E. Paraneoplastic syndrome

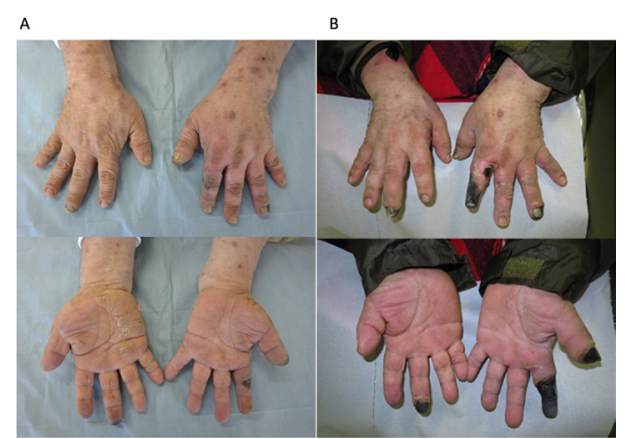

Figure 1 (A) Initial manifestation at the previous hospital. Note the ulcers in the bilateral fingers. (B) Development to finger necrosis on his admission in our hospital.

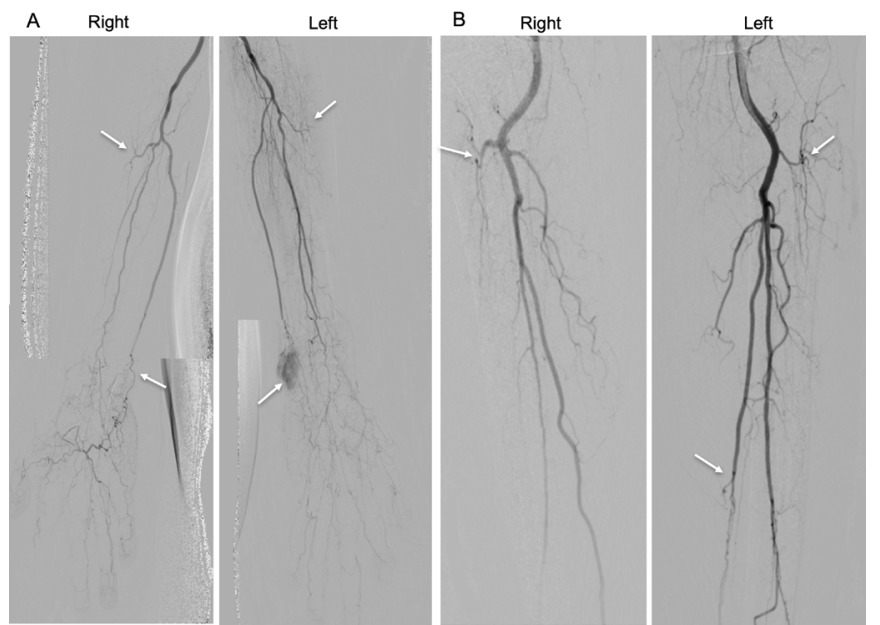

Figure 2 (A) Upper extremity angiography revealed extensive occlusions in the bilateral radial and ulnar arteries (arrow). (B) Lower extremity angiography revealed multiple occlusions in the right anterior tibial artery, the left anterior tibial artery and the left posterior tibial artery (arrow).

A

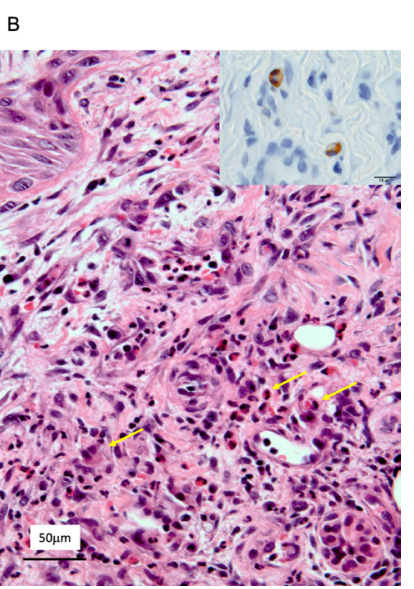

Figure 3 (A) Skin biopsy from the border of the finger necrosis demonstrated nodular inflammatory cell infiltration in dermis and subcutaneous tissue (H\&E stain). (B) Magnified histopathological examination of the skin biopsy found eosinophilic infiltration (arrows) in granulomatous inflammation of upper dermis (H\&E stain). Immunohistochemistry (inset) showing major basic protein of eosinophils (immunostaining). 


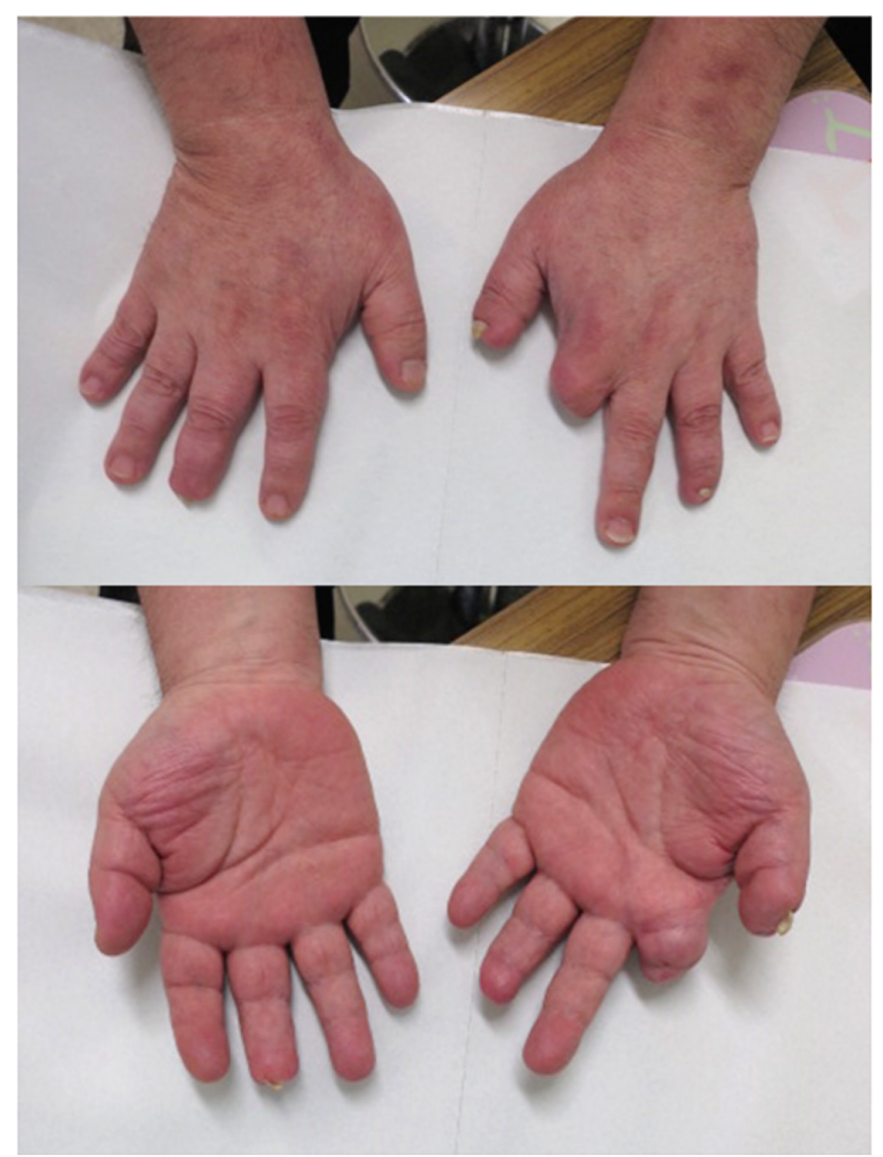

Figure 4 Complete wound healing 5 months later following the initiation of prednisone.

\section{ANSWER: B}

Finger necrosis and symmetrical occlusion of the peripheral artery can be caused by a wide range of vascular disorders. ${ }^{1}$ In this case, an evidence of peripheral blood eosinophilia ( $>10 \%$ of total white blood cell) with elevated IgE and perivascular infiltration of eosinophils were the clue to diagnosis.

Eosinophilic vasculitis typically can be caused by two forms; one is idiopathic eosinophilic vasculitis characterised by recurrent episodes of pruritic papules, urticaria and angioedema without immunoserological findings, and another is due to connective tissue disease, eosinophilic granulomatosis with polyangiitis (EGPA). ${ }^{2}$ In this case, medical history of asthma and lung involvement that are documented in the American College of Rheumatology classification criteria and the Chapel Hill consensus conference definition for EGPA were lacking. ${ }^{3} 4$ However, given the evidence of eosinophilia with elevated $\operatorname{IgE}$ and perivascular eosinophilic infiltration in granulomatous inflammation of dermis on biopsy, multidisciplinary discussion led to the diagnosis of EGPA or a rare entity of eosinophilic vasculitis with thrombotic complication. ${ }^{5}$ It is recognised that eosinophilic vasculitis is responsive to corticosteroid therapy. Indeed, a high-dose glucocorticoid (prednisone, $0.8 \mathrm{mg} / \mathrm{kg} / \mathrm{day}$ ) was initiated, and no further development of finger necrosis or systemic disorders was observed. His hand skin perfusion pressure was $97 / 68 \mathrm{mmHg}$ (palmar/dorsal) in the right and $49 / 45 \mathrm{~mm} \mathrm{Hg}$ in the left, suggesting a high likelihood of wound healing. With a tapering prednisone dose, his eosinophilia and inflammation normalised, and medical management facilitated complete wound healing following autoamputation 5 months later (figure 4). No recurrence has been observed during the last 2 years.

\section{Ryo Nishikawa, ${ }^{\oplus 1}$ Toru Hirano, $^{2}$ Osami Kawarada ${ }^{1,3}$}

${ }^{1}$ Department of Cardiovascular Medicine, National Cerebral and Cardiovascular Center, Suita, Japan

${ }^{2}$ Department of Allergy and Rheumatic Diseases, Osaka University, Suita, Japan ${ }^{3}$ Department of Cardiovascular Medicine, Ikuwakai Memorial Hospital, Osaka, Japan

Correspondence to Dr Osami Kawarada, Department of Cardiovascular Medicine, Ikuwakai Memorial Hospital, 3-20-29 Tatsumikita, Ikunoku, Osaka 544-0004, JAPAN; osamikawarada@yahoo.co.jp

Collaborators Shinobu Ayabe; Takeshi Yagyu; Hatsue Ishibashi-Ueda.

Contributors RN, TH and OK were involved in the clinical management of the patient. RN drafted and OK revised the manuscript.

Funding The authors have not declared a specific grant for this research from any funding agency in the public, commercial or not-for-profit sectors.

Competing interests None declared.

Patient consent for publication Obtained.

Provenance and peer review Not commissioned; externally peer reviewed.

(c) Author(s) (or their employer(s)) 2019. No commercial re-use. See rights and permissions. Published by BMJ.

$$
\text { D) Check for updates }
$$

To cite Nishikawa R, Hirano T, Kawarada O. Heart Asia 2019;11:e011211.

Heart Asia 2019;11:e011211. doi:10.1136/heartasia-2019-011211

\section{REFERENCES}

1. Shiba M, leko M, Kawarada O. Symmetric peripheral gangrene in antiphospholipid syndrome. Heart Asia 2016;8:8.

2. Valent $\mathrm{P}$, Klion $A D$, Horny $H-P$, et al. Contemporary consensus proposal on criteria and classification of eosinophilic disorders and related syndromes. J Allergy Clin Immunol 2012;130:607-12

3. Masi AT, Hunder GG, Lie JT, et al. The American College of Rheumatology 1990 criteria for the classification of Churg-Strauss syndrome (allergic granulomatosis and angiitis). Arthritis Rheum 1990;33:1094-100.

4. Jennette JC, Falk RJ, Bacon PA, et al. 2012 revised International Chapel Hill Consensus Conference Nomenclature of Vasculitides. Arthritis Rheum 2012;2013:1-11.

5. Law $A D$, Varma $S$, Varma $N$, et al. Eosinophilic vasculitis: time for recognition of a new entity? Indian J Hematol Blood Transfus 2014;30(Suppl 1):325-30. 